\title{
Influence of Perceptions of Death, End-of-Life Care Stress, and Emotional Intelligence on Attitudes towards End-of-Life Care among Nurses in the Neonatal Intensive Care Unit
}

\author{
Ju-Young Park ${ }^{1}$, Jina $\mathrm{Oh}^{2}$ \\ ${ }^{1}$ Adjunct Professor, Dongwon Institute of Science and Technology, Busan; ${ }^{2}$ Professor, Department of Nursing, School of Medicine, Inje University, Busan, Korea
}

Purpose: The purpose of this study was to investigate the influence of perceptions of death, end-of-life (EOL) care stress, and emotional intelligence on attitudes toward EOL care among nurses in the neonatal intensive care unit (NICU). Methods: The participants were 111 nurses working in a NICU who had experienced EOL care at least once. Data were analyzed using the t-test, Pearson correlation coefficient, and stepwise multiple regression analysis in SPSS for Windows. Results: The mean score for perceptions of death was 3.16 out of 5, the mean score for EOL care stress was 3.61 out of 5, the mean emotional intelligence score was 4.66 out of 7 , and the average score for EOL care attitudes was 2.77 out of 4 . The factors affecting attitudes towards EOL care were academic degree, anxiety regarding death, negativity towards death, experiences of patient death, and emotional intelligence. The explanatory power of these variables for attitudes towards EOL care was $24.7 \%$. Conclusion: The results of this study are expected to serve as a basic reference for the development of nursing education programs and EOL care protocols to improve attitudes toward EOL care among NICU nurses.

Key words: Newborn; Critical care; Emotional intelligence; Terminal care; Attitude

\section{Corresponding author Jina Oh}

https://orcid.org/0000-0002-5883-7538

Department of Nursing, School of Medicine, Inje University,

75 Bokji-ro, Busanjin-gu, Busan 47392, Korea

TEL +82-51-890-6833 FAX +82-51-896-9840

E-MAIL ohjina@inje.ac.kr

*This article was adapted from a thesis by Ju-Young Park in partial fulfillment of the requirements for the master's degree at Inje University.

Received Oct 15, 2018 Revised Nov 11, 2018 Accepted Dec 3, 2018
(2) This is an Open Access article distributed under the terms of the Creative Commons Attribution NonCommercial License (http://creativecommons.org/licenses/by-nc/4.0/) which permits unrestricted noncommercial use, distribution, and reproduction in any medium, provided the original work is properly cited.

\section{INTRODUCTION}

\section{Importance of Research}

The number of births in Korea decreased from 493,000 in 2007 to 358,000 in 2017, reaching a record low in the past decade, and the proportion of high-risk newborns due to older maternal age, infertility, and difficulties in birth grew from $3.8 \%$ in 2010 to $4.7 \%$ in 2014 [1]. In addition, despite developments in medical technology, deaths due to respiratory diseases, fetal developmental disorders, and congenital heart malformations accounted for $74.8 \%$ of the 1,305 infant deaths that occurred in 2014 [1]. Newborns with critical health problems are managed in the neonatal intensive care unit (NICU), in which nurses care for high-risk newborns at the forefront of clinical care, in an environment that requires frequent interventions and highly-developed skills for handling emergencies [2].

One of the typical challenges faced by NICU nurses is experiencing the death of newborns that they have cared for [3]. In recent years, efforts have been made to apply end-of-life (EOL) care practices for newborns, as the awareness of the necessity of newborn EOL care has increased [4]. However, in- 
sufficient basic data have been gathered in relation to newborn EOL care, as no institutions in Korea systematically provide newborn EOL care due to a lack of standardization, insufficient expertise in newborn EOL care, and negative attitudes towards EOL care [5]. In particular, a nurse who has a strong attachment to a newborn may experience deep sorrow, guilt, and regret, since the newborn has become special to the nurse [6]. Moreover, nurses who are not well-prepared for EOL care may go through negative experiences when caring for dying newborns [5]. As a first step towards addressing these problems, it is necessary to identify the factors influencing the attitudes of NICU nurses towards EOL care, as negative attitudes such as the perception of a burden, fear, and frustration can adversely affect nursing performance [4]. In contrast, sufficient preparation for EOL care and positive attitudes may facilitate a decent and dignified life and death for the patient and his or her family [7].

Attitudes towards EOL care reflect nurses' perceptions, emotions, and motivations for overall care that meets the physical, mental, social, and spiritual needs of a dying patient and his or her family [8]. Previous studies of the factors affecting attitudes toward EOL care did not show a correlation between relevant variables and attitudes towards EOL care, but insufficient research has investigated the possible link between attitudes towards EOL care and the newly-emerging concept of emotional intelligence. In addition, no studies have investigated attitudes towards EOL care in NICU nurses. Therefore, identifying the factors affecting EOL care attitudes among NICU nurses will be useful in the development of concrete proposals for improving the quality of EOL care.

Perceptions of death reflect attitudes towards life when looking at death [9]. Nurses should establish a definite awareness of death based on a solid understanding in order to minimize their stress and loss and to perform EOL care as well as possible, even though doing so requires repeated exposure to EOL situations [10]. Positive perceptions of death reduce fear and anxiety regarding death [11], while negative perceptions of death cause nurses to experience limitations when nursing patients who are in pain and when handling death-avoiding behaviors in patients [12]. Although perceptions of death are considered to be a major factor affecting attitudes towards EOL care, a prior study showed no significant correlation [13], suggesting that this issue should be re-investigated.

The death of a newborn cared for by a NICU nurse often causes the nurse to experience a high level of EOL care stress. EOL care stress refers to a situation in which a nurse is burdened by work while providing comprehensive and holistic care to a dying patient and his or her family [14]. EOL stress can be considered a major obstacle to EOL care, because it reduces the quality of nursing care and affects nurses' attitudes towards EOL care [15].

In contrast, emotional intelligence is the ability to understand the emotions of oneself and others, and to efficiently utilize one's emotions by appropriately adjusting to situations [16]. Emotional intelligence has recently come into the spotlight as an intrinsic variable that can help individuals overcome job stress, which negatively affects themselves and their organization [17]. According to previous studies, higher emotional intelligence was accompanied by higher interpersonal ability and job satisfaction [18]. Since nurses who provide EOL care are expected to exhibit emotional control, it is expected that emotional intelligence would be associated with positive attitudes towards EOL care, but no studies have specifically investigated this possible relationship.

Therefore, this study aimed to provide basic data to support the development of nursing education programs and EOL care protocols, with the goal of improving attitudes towards EOL care, by identifying the effects of perceptions of death, EOL care stress, and emotional intelligence on attitudes toward EOL care among NICU nurses.

\section{Objectives}

The purpose of this study was to identify the effects of NICU nurses' perceptions of death, EOL care stress, and emotional intelligence on attitudes towards EOL care, with the ultimate goal of improving the attitudes of NICU nurses towards EOL care and the quality of EOL care. The specific purposes of this study were (a) to identify the general characteristics of the subjects and their perceptions of death, EOL care stress, emotional intelligence, and attitudes towards EOL care, (b) to analyze correlations among the subjects' perceptions of death, EOL care stress, emotional intelligence, and attitudes towards EOL care, and (c) to identify the factors that influenced the subjects' attitudes towards EOL care.

\section{METHODS}

\section{Design}

This descriptive study was conducted to investigate the effects of NICU nurses' perceptions of death, EOL care stress, and emotional intelligence on attitudes toward EOL care.

\section{Subjects}

This study was conducted among nurses from three university hospitals in $\mathrm{U}$ metropolitan city, $\mathrm{Y}$ city, and $\mathrm{K}$ city, and two general hospitals in B metropolitan city, with at least one month of working experience in the NICU and at least one ex- 
perience of EOL care. The sample size needed for the study was calculated using $G^{*}$ Power version 3.1.9.2. The minimum sample size was 109 based on a medium effect size of .15, a significance level of .05 , a power of $80 \%$, and eight predictive variables (perceptions of death, stress of EOL care, and emotional intelligence, as well as highest level of education, length of clinical career, occupational position, marital status, and prior education in EOL care, which were found to be explanatory variables in previous studies). Data were collected from 120 subjects, considering about 10\% dropout rate, and data from 111 questionnaires were utilized, with the exclusion of nine questionnaires with incomplete and/or insincere replies.

\section{Ethical Considerations and Data Collection Method- ology}

This study was conducted after receiving approval from the Bioethics Committee of I University (IRB number: 201709-021-001), and the data collection period was from November 1, 2017 to February 10, 2018. The researcher either visited or sent an e-mail to explain the intent, purpose, and the data collection method, and after receiving approval from the nursing department, visited the NICU to provide specific explanations of the details and purpose of the study to the participating nurses. The explanatory text included statements indicating that participation in the study was voluntary and withdrawal was possible at any time, that the questionnaire would only be used for research purposes, and that anonymity was guaranteed. The subjects of the study read the description of the details and purpose of the study and provided written consent. It took about 15 minutes to complete the questionnaire, and all nurses who participated in the study were provided a pen of 1,000 won.

\section{Research Tools}

\section{1) Perceptions of death}

The tool developed by Cha [19] by modifying and supplementing the perceptions of life and death scale created by Yoshiyuki [9] was used after receiving approval from the author. Cha [19] applied the tool in a study of 290 nurses, and since then, many researchers have administered it to nurses [12], thereby ensuring its validity. This tool comprises 36 questions in five subdomains, including 10 questions on positivity towards death questions, 10 on negativity towards death, five on anxiety regarding death, five on interest in death, and six questions on the will to respect for live. Each item is scored on a 5-point Likert scale, with higher scores indicating higher perceptions of death. When the tool was developed, the Cronbach's $\alpha$ was .71 overall, with a distribution by subdomain of .77 for positivity towards death, .72 for negativity towards death, .87 for anxiety regarding death, .84 for interest in death, and .77 for respect for the will to live [9]. In this study, the Cronbach's $\alpha$ was .79 overall, with a distribution by subdomain of 80 for positivity towards death, .78 for negativity towards death, .86 for anxiety regarding death, .90 for interest in death, and .65 for respect for the will to live.

\section{2) End-of-life care stress}

The tool for measuring stress of EOL care among NICU nurses developed by Jang [15] was used after receiving approval from the author. This tool is composed of 29 questions, with five subdomains: six questions on difficulties involved in related to EOL care, five questions on lack of knowledge, 10 questions on difficulties in the physical and structural environment, and eight questions on emotional stress. Each question is scored on a 5-point Likert scale, with higher scores indicating higher levels of EOL care stress. When the tool was developed, the Cronbach's $\alpha$ was .86 overall, with a distribution by subdomain of .73 for difficulties involved in related to EOL care, .75 for lack of knowledge, .86 for difficulties in the physical and structural environment, and .81 for emotional stress [15]. In this study, the Cronbach's $\alpha$ was .94 overall, with a distribution by subdomain of .83 for difficulties involved in related to EOL care, .82 for lack of knowledge, .90 for difficulties in the physical and structural environment, and .84 for emotional stress.

\section{3) Emotional intelligence}

The tool developed by Jung and Kim [20] by translating the Wong and Law Emotional Intelligence Scale (WLEIS) [16] was used after receiving approval from the authors. Jung and Kim [20] applied this tool in a study of 481 workers, and since then, many researchers have administered it to nurses [21], thereby ensuring its validity. This tool is composed of 16 questions, with four subdomains: self-emotion appraisal, others' emotion appraisal, regulation of emotion, and use of emotion. Each subdomain is composed of four questions scored on a 7-point Likert scale, with higher scores indicating higher emotional intelligence. When the tool was developed, the Cronbach's $\alpha$ was .87 overall, with a distribution by subdomain of .92 for self-emotion appraisal, .91 for others' emotion appraisal, .84 for regulation of emotion, and .93 for use of emotion [16]. In this study, the Cronbach's $\alpha$ was .92 overall, with a distribution by subdomain of .85 for self-emotion appraisal, .86 for others' emotion appraisal, .81 for regulation of emotion, and .82 for use of emotion.

\section{4) Attitudes towards end-of-life care}

The tool developed by Cho and Kim [22] by translating the 
Frommelt Attitudes toward Nursing Care of the Dying Scale (FATCOD) [23] was used. Cho and Kim [22] developed a Korean version of the tool to be used for research into the attitudes of nursing students, and since then, many researchers have administered it to nurses $[13,24]$, thereby ensuring its validity. This tool is composed of 30 questions, including 20 questions on attitudes towards individual terminal patients and 10 questions on attitudes towards family members. Each question consists of a 4-point Likert scale, and points for negative questions are inversely converted. Higher scores indicate more positive perceptions, emotions, and motivations toward EOL care, corresponding to positive attitudes towards EOL care. When the tool was developed, the Cronbach's $\alpha$ was .94 [23]; it was .86 in the study conducted by Cho and Kim [22], and .71 in this study.

\section{Data Analysis Methodology}

The collected data were analyzed using SPSS for Windows version 23.0 (IBM Corp. Armonk, NY, USA). The general characteristics of the subjects were analyzed as frequency and percentage or as mean and standard deviation, and the subjects' scores for perceptions of death, EOL care stress, emotional intelligence, and attitudes towards EOL care were analyzed as mean and standard deviation. Differences in each variable according to subjects' general characteristics were verified using the t-test or one-way analysis of variance, and post-verified by the Scheffé test. In addition, the relationships between variables were analyzed using the Pearson correlation coefficient, and the factors affecting attitudes towards
EOL care were analyzed using stepwise multiple regression.

\section{RESULTS}

\section{Perceptions of Death, End-of-Life Care Stress, Emo- tional Intelligence, and Attitudes towards End-of- Life Care}

The subjects' average score for perceptions of death was 3.16 out of 5 . The highest score was found for negativity towards death, followed in order by respect for the will to live, anxiety regarding death, positivity towards death, and interest in death. The average score for EOL care stress was 3.61 out of 5 points. The highest score was for difficulties involved in related to EOL care, followed in order by difficulties in the physical and structural environment, lack of knowledge, and emotional stress. The average score for emotional intelligence was 4.66 out of 7 points. The highest score was found for selfemotion appraisal, followed in order by others' emotion appraisal, use of emotion, and regulation of emotion. The average score for attitudes towards EOL care was 2.77 out of 4 points (Table 1).

\section{Differences in Perceptions of Death, End-of-Life Care Stress, Emotional Intelligence, and Attitudes towards End-of-Life Care according to Subjects General Characteristics}

Most of the subjects were female $(99.1 \%)$, with an average age of 29.2 years, and $22.5 \%$ were married, while $13.5 \%$ had

Table 1. Descriptive Statistics for Perceptions of Death, End-of-Life Care Stress, Emotional Intelligence, and Attitudes towards End-of-Life Care

\begin{tabular}{|c|c|c|c|c|}
\hline Variables and subcategories & $\mathrm{M} \pm \mathrm{SD}$ & Min & $\operatorname{Max}$ & Range \\
\hline Perceptions of death (total) & $3.16 \pm 0.34$ & 2.11 & 3.89 & $1 \sim 5$ \\
\hline Positivity towards death & $3.02 \pm 0.54$ & 1.50 & 5.00 & $1 \sim 5$ \\
\hline Negativity towards death & $3.56 \pm 0.52$ & 2.30 & 5.00 & $1 \sim 5$ \\
\hline Anxiety regarding death & $3.07 \pm 0.07$ & 1.00 & 5.00 & $1 \sim 5$ \\
\hline Interest in death & $2.78 \pm 0.07$ & 1.00 & 5.00 & $1 \sim 5$ \\
\hline Respect for the will to live & $3.09 \pm 0.55$ & 1.67 & 4.67 & $1 \sim 5$ \\
\hline EOL care stress (total) & $3.61 \pm 0.61$ & 1.17 & 5.00 & $1 \sim 5$ \\
\hline Difficulties involved in related to EOL care & $3.67 \pm 0.71$ & 1.50 & 5.00 & $1 \sim 5$ \\
\hline Lack of knowledge & $3.63 \pm 0.64$ & 1.40 & 5.00 & $1 \sim 5$ \\
\hline Difficulties in the physical and structural environment & $3.65 \pm 0.66$ & 1.00 & 5.00 & $1 \sim 5$ \\
\hline Emotional stress & $3.49 \pm 0.64$ & 1.00 & 5.00 & $1 \sim 5$ \\
\hline Emotional intelligence (total) & $4.66 \pm 0.70$ & 2.81 & 6.19 & $1 \sim 7$ \\
\hline Self-emotion appraisal & $4.89 \pm 0.81$ & 2.75 & 6.75 & $1 \sim 7$ \\
\hline Others' emotion appraisal & $4.86 \pm 0.77$ & 2.75 & 6.50 & $1 \sim 7$ \\
\hline Regulation of emotion & $4.63 \pm 0.78$ & 2.25 & 6.25 & $1 \sim 7$ \\
\hline Use of emotion & $4.24 \pm 0.87$ & 2.00 & 7.00 & $1 \sim 7$ \\
\hline EOL care attitudes & $2.77 \pm 0.21$ & 2.31 & 3.31 & $1 \sim 4$ \\
\hline
\end{tabular}

EOL=End-of-life. 
children. Only $25.0 \%$ of the subjects who reported a religious affiliation (36.0\%) stated that they were faithfully living a religious life. Most of the subjects were general nurses (87.4\%); $46.9 \%$ of the subjects had a total clinical career of less than 5 years, while $55.0 \%$ had a NICU clinical career of less than 5 years. On average, the subjects had experienced deaths of their patients 7.32 times, and $36.0 \%$ had experienced the death of an immediate family member during their period of duty. Furthermore, $72.1 \%$ of the subjects had not received EOL care education (Table 2).

No statistically significant differences were found in perceptions of death and EOL care stress according to the general characteristics of the subjects. However, emotional intelligence showed a significant association with occupational position, academic degree, and whether the subject had received
EOL care education. Specifically, emotional intelligence was higher among charge nurses than among general nurses $(\mathrm{t}=$ $2.01, p=.047$ ), higher among those with at least a bachelor or a master's degree than among those with an associate degree $(\mathrm{F}=3.73, p=.027)$, and higher among those who had received EOL care education than among those who had not $(\mathrm{t}=2.00$, $p=.047$ ). In contrast, attitudes towards EOL care showed statistically significant relationships with a and the number of times a subject had experienced the death of a patient. Attitudes towards EOL care were more positive among those with at least a master's degree than among those with an associate or a bachelor degree $(\mathrm{F}=7.44, p<.001)$ and among those who had experienced the death of a patient at least 11 times $(\mathrm{F}=$ $4.77, p=.010$ ) (Table 2).

Table 2. Differences in Perceptions of Death, End-of-Life Care Stress, Emotional Intelligence, and Attitudes towards End-of-Life Care by General Characteristics

$(N=111)$

\begin{tabular}{|c|c|c|c|c|c|c|c|c|c|c|}
\hline \multirow[t]{2}{*}{ Variables } & \multirow[t]{2}{*}{ Categories } & \multirow[t]{2}{*}{$\mathrm{n}(\%)$} & \multicolumn{2}{|c|}{$\begin{array}{l}\text { Perceptions of } \\
\text { death }\end{array}$} & \multicolumn{2}{|c|}{$\begin{array}{c}\text { EOL } \\
\text { care stress }\end{array}$} & \multicolumn{2}{|c|}{$\begin{array}{l}\text { Emotional } \\
\text { intelligence }\end{array}$} & \multicolumn{2}{|c|}{$\begin{array}{c}\text { EOL } \\
\text { care attitude }\end{array}$} \\
\hline & & & $\mathrm{M} \pm \mathrm{SD}$ & $t$ or $F(p)$ & $\mathrm{M} \pm \mathrm{SD}$ & t or $F(p)$ & $\mathrm{M} \pm \mathrm{SD}$ & t or $\mathrm{F}(p)$ & $\mathrm{M} \pm \mathrm{SD}$ & tor $F(p)$ \\
\hline \multirow[t]{3}{*}{ Age (year) } & & 45 (40.6) & $3.13 \pm 0.37$ & \multirow{3}{*}{$\begin{array}{c}0.36 \\
(.694)\end{array}$} & $3.60 \pm 0.55$ & \multirow{3}{*}{$\begin{array}{c}1.19 \\
(.308)\end{array}$} & $4.62 \pm 0.65$ & \multirow{3}{*}{$\begin{array}{c}0.43 \\
(.647)\end{array}$} & $2.75 \pm 0.21$ & \multirow{3}{*}{$\begin{array}{c}1.31 \\
(.272)\end{array}$} \\
\hline & $\sim 30$ & 33 (29.7) & $3.16 \pm 0.28$ & & $3.74 \pm 0.54$ & & $3.16 \pm 0.28$ & & $2.75 \pm 0.16$ & \\
\hline & 31 & 33 (29.7) & $3.20 \pm 0.36$ & & $3.51 \pm 0.74$ & & $4.76 \pm 0.76$ & & $2.82 \pm 0.24$ & \\
\hline \multirow[t]{2}{*}{ Marital status } & Single & $86(77.5)$ & $3.17 \pm 0.33$ & \multirow{2}{*}{$\begin{array}{c}0.35 \\
(.724)\end{array}$} & $3.65 \pm 0.62$ & \multirow{2}{*}{$\begin{array}{l}1.23 \\
(.221)\end{array}$} & $4.65 \pm 0.68$ & \multirow{2}{*}{$\begin{array}{c}0.27 \\
(.788)\end{array}$} & $2.76 \pm 0.21$ & \multirow{2}{*}{$\begin{array}{cc}1 & 0.60 \\
0 & (.547)\end{array}$} \\
\hline & Marrie & $25(22.5)$ & $3.14 \pm 0.39$ & & $3.48 \pm 0.54$ & & $4.70 \pm 0.78$ & & $2.79 \pm 0.20$ & \\
\hline \multirow[t]{2}{*}{ Child } & Yes & 15 (13.5) & $3.24 \pm 0.36$ & \multirow{2}{*}{$\begin{array}{c}0.99 \\
(.322)\end{array}$} & $3.63 \pm 0.61$ & \multirow{2}{*}{$\begin{array}{c}0.99 \\
(.323)\end{array}$} & $4.67 \pm 0.94$ & \multirow{2}{*}{$\begin{array}{c}0.03 \\
(.976)\end{array}$} & $2.77 \pm 0.22$ & \multirow{2}{*}{$\begin{array}{cc}2 & 0.08 \\
1 & (.934)\end{array}$} \\
\hline & No & $96(86.5)$ & $3.15 \pm 0.34$ & & $3.47 \pm 0.58$ & & $4.66 \pm 0.66$ & & $2.77 \pm 0.21$ & \\
\hline \multirow[t]{2}{*}{ Religion } & Yes & $40(36.0)$ & $3.16 \pm 0.35$ & \multirow{2}{*}{$\begin{array}{c}0.07 \\
(.939)\end{array}$} & $3.70 \pm 0.53$ & \multirow{2}{*}{$\begin{array}{l}1.09 \\
(.277)\end{array}$} & $4.78 \pm 0.70$ & \multirow{2}{*}{$\begin{array}{c}1.37 \\
(.172)\end{array}$} & $2.81 \pm 0.20$ & \multirow{2}{*}{$\begin{array}{cc}0 & 1.45 \\
1 & (.150)\end{array}$} \\
\hline & No & $71(64.0)$ & $3.16 \pm 0.34$ & & $3.56 \pm 0.65$ & & $4.59 \pm 0.70$ & & $2.75 \pm 0.21$ & \\
\hline \multirow{2}{*}{$\begin{array}{l}\text { Religious life } \\
\quad(\mathrm{n}=40)\end{array}$} & Very & $10(25.0)$ & $3.17 \pm 0.35$ & 0.06 & $3.61 \pm 0.67$ & 060 & $4.84 \pm 0.80$ & (2) & $2.91 \pm 0.23$ & 188 \\
\hline & $\mathrm{N}$ & $30(75.0)$ & $3.16 \pm 0.35$ & $(.953)$ & $3.73 \pm 0.49$ & $(.550)$ & $4.76 \pm 0.68$ & $(.780)$ & $2.77 \pm 0.18$ & $(.067)$ \\
\hline Position & Staff nurse & $97(87.4)$ & $3.15 \pm 0.35$ & 070 & $3.63 \pm 0.59$ & 079 & $4.61 \pm 0.70$ & 201 & $2.76 \pm 0.19$ & 1.00 \\
\hline & $\geq \mathrm{Ch}$ & 14 (12.6) & $3.22 \pm 0.29$ & $(.483)$ & $3.49 \pm 0.75$ & $(.427)$ & $5.01 \pm 0.65$ & $(.047)$ & $2.82 \pm 0.28$ & $(.317)$ \\
\hline & $<5$ & $52(46.9)$ & $3.13 \pm 0.37$ & 135 & $3.68 \pm 0.59$ & 1.50 & $4.60 \pm 0.64$ & 0.97 & $2.74 \pm 0.20$ & 1.98 \\
\hline & $6 \sim 10$ & $40(36.0)$ & $3.14 \pm 0.30$ & $(.262)$ & $3.62 \pm 0.47$ & $(.227)$ & $4.64 \pm 0.74$ & $(.382)$ & $2.77 \pm 0.20$ & (.143) \\
\hline & $\geq 11$ & $19(17.1)$ & $3.28 \pm 0.33$ & & $3.40 \pm 0.86$ & & $4.86 \pm 0.78$ & & $2.85 \pm 0.22$ & \\
\hline Clinical career & & $61(55.0)$ & $3.15 \pm 0.37$ & 0.12 & $3.66 \pm 0.57$ & 0.36 & $4.62 \pm 0.72$ & 0.40 & $2.73 \pm 0.20$ & 2.32 \\
\hline in NICU (year) & $6 \sim 10$ & 39 (35.1) & $3.16 \pm 0.31$ & $(.884)$ & $3.57 \pm 0.66$ & (.695) & $4.64 \pm 0.74$ & $(.666)$ & $2.80 \pm 0.21$ & $(.103)$ \\
\hline & $\geq 11$ & $11(9.9)$ & $3.20 \pm 0.32$ & & $3.53 \pm 0.67$ & & $4.86 \pm 0.78$ & & $2.86 \pm 0.22$ & \\
\hline Academic degree & Associate $^{\mathrm{a}}$ & 15 (13.5) & $3.16 \pm 0.38$ & 0.16 & $3.63 \pm 0.50$ & 1.17 & $4.24 \pm 0.77$ & 3.73 & $2.67 \pm 0.16$ & 7.44 \\
\hline & Bachelor $^{\mathrm{b}}$ & $86(77.5)$ & $3.15 \pm 0.34$ & $(.847)$ & $3.64 \pm 0.56$ & $(.313)$ & $4.70 \pm 0.68$ & $(.027)$ & $2.76 \pm 0.20$ & $(<.001)$ \\
\hline & $\geq$ Master's $^{c}$ & $10(9.0)$ & $3.22 \pm 0.30$ & & $3.33 \pm 1.02$ & & $4.93 \pm 0.62$ & $\mathrm{a}<\mathrm{b}, \mathrm{c}^{*}$ & $2.98 \pm 0.21$ & $\mathrm{a}, \mathrm{b}<\mathrm{c}^{*}$ \\
\hline Total experiences & $1 \sim 5^{\mathrm{a}}$ & $48(43.3)$ & $3.16 \pm 0.34$ & 0.00 & $3.64 \pm 0.58$ & & $4.64 \pm 0.57$ & 0.03 & $2.76 \pm 0.19$ & 4.77 \\
\hline of patient death & $6 \sim 10^{b}$ & $29(26.1)$ & $3.16 \pm 0.37$ & $(>.999)$ & $3.61 \pm 0.60$ & $(.888)$ & $4.68 \pm 0.88$ & $(.968)$ & $2.70 \pm 0.20$ & $(.010)$ \\
\hline & $\geq 11^{\mathrm{c}}$ & $34(30.6)$ & $3.16 \pm 0.33$ & & $3.58 \pm 0.67$ & & $4.67 \pm 0.71$ & & $2.85 \pm 0.22$ & $a, b<c^{*}$ \\
\hline Prior education & Yes & $31(27.9)$ & $3.17 \pm 0.33$ & 0.12 & $3.69 \pm 0.73$ & 0.88 & $4.87 \pm 0.70$ & 2.00 & $2.81 \pm 0.20$ & 1.19 \\
\hline & No & $80(72.1)$ & $3.16 \pm 0.35$ & $(.899)$ & $3.58 \pm 0.55$ & $(.377)$ & $4.58 \pm 0.69$ & $(.047)$ & $2.75 \pm 0.21$ & $(.236)$ \\
\hline Experience of a & No & $71(64.0)$ & $3.16 \pm 0.37$ & 0.20 & $3.69 \pm 0.55$ & 2.21 & $4.72 \pm 0.71$ & 0.76 & $2.77 \pm 0.21$ & 0.30 \\
\hline family member's & 1 & $26(23.4)$ & $3.13 \pm 0.26$ & $(.814)$ & $3.54 \pm 0.47$ & $(.115)$ & $4.58 \pm 0.73$ & $(.469)$ & $2.75 \pm 0.18$ & $(.740)$ \\
\hline death & $\geq 2$ & $14(12.6)$ & $3.20 \pm 0.32$ & & $3.34 \pm 0.97$ & & $4.51 \pm 0.59$ & & $2.80 \pm 0.25$ & \\
\hline
\end{tabular}

*Scheffé test, $p<.050$; EOL=End-of-life; NICU=Neonatal intensive care unit. 


\section{Correlations among Subjects' Perceptions of Death, End-of-Life Care Stress, Emotional Intelligence, and Attitudes towards End-of-Life Care}

Table 3 shows correlations among subjects' perceptions of death (positivity towards death, negativity towards death, anxiety regarding death, interest in death, and respect for the will to live), EOL care stress, emotional intelligence, and attitudes towards EOL care. Especially, each subdomain of perceptions of death was analyzed and compared separately, because each interpretation of result really represents differ according to subdomain.

Positive correlations were found between positivity towards death and interest in death $(\mathrm{r}=.29, p=.002)$, positivity towards death and EOL care stress $(\mathrm{r}=.33, p<.001)$, anxiety regarding death and interest in death $(\mathrm{r}=.41, p<.001)$, respect for the will to live and emotional intelligence $(\mathrm{r}=.26, p=.007)$, and emotional intelligence and attitudes towards EOL care $(\mathrm{r}=.21, p=.028)$. Negative correlations were found between negativity towards death and attitudes towards EOL care $(\mathrm{r}=-.24, p=.013)$ and between anxiety regarding death and attitudes towards EOL care $(\mathrm{r}=-.23, p=.017)$.

\section{Factors affecting Attitudes towards End-of-Life Care}

A multiple regression analysis was conducted with the subjects' attitude towards EOL care as the dependent variable, and academic degree (as a general characteristics of subjects that had a significant effect on attitudes towards EOL care), negativity towards death and anxiety regarding death (as subdomains of perceptions of death that had a significant correlation with the number of times that subjects had experienced patients' deaths and attitudes towards EOL care), and emotional intelligence as independent variables (Table 4). Nominal variables, including academic degree (at least a master's degree) and the number of times a subject had experienced the death of a patient (at least 11 times) were analyzed using dummy variables. As a result of examining the multiple regression function hypothesis, the Durbin-Watson statistic was 2.06 and there was no autocorrelation, the tolerance limit for finding the variance inflation factor (VIF) was .93 1.00 and was higher than .10 in all cases, the VIF was lower than 10 (1.00 1.10), and there was no multicollinearity. The results of the analysis showed that the factors affecting attitudes towards EOL care were academic degree $(\beta=.23, p=.010)$, number of experiences of a patient's death $(\beta=.18, p=.038)$, negativity towards death $(\beta=-.17, p=.047)$, anxiety regarding death $(\beta=-.21, p=.015)$, and emotional intelligence $(\beta=.18$, $p=.042$ ). In other words, the higher the academic degree, the more times a subject had experienced patients' deaths, the lower the score for negativity towards death, the lower the score for anxiety regarding death, and the higher the emotional intelligence, the more positive the attitude towards EOL care. The explanatory power of these variables for attitudes to-

Table 3. Correlations among Perceptions of Death, End-of-Life Care Stress, Emotional Intelligence, and Attitudes towards End-of-Life Care

\begin{tabular}{|c|c|c|c|c|c|c|c|c|}
\hline \multirow{3}{*}{ Variables } & \multirow{3}{*}{ Categories } & \multicolumn{5}{|c|}{ Perceptions of death } & \multirow[b]{2}{*}{$\begin{array}{c}\text { EOL } \\
\text { care } \\
\text { stress }\end{array}$} & \multirow[b]{2}{*}{$\begin{array}{l}\text { Emotional } \\
\text { intelligence }\end{array}$} \\
\hline & & $\begin{array}{c}\text { Positivity } \\
\text { towards } \\
\text { death }\end{array}$ & $\begin{array}{l}\text { Negativity } \\
\text { towards } \\
\text { death }\end{array}$ & $\begin{array}{l}\text { Anxiety } \\
\text { regarding } \\
\text { death }\end{array}$ & $\begin{array}{l}\text { Interest } \\
\text { in death }\end{array}$ & $\begin{array}{l}\text { Respect } \\
\text { for the will } \\
\text { to live }\end{array}$ & & \\
\hline & & $\mathrm{r}(p)$ & $r(p)$ & $r(p)$ & $\mathrm{r}(p)$ & $\mathrm{r}(p)$ & $\mathrm{r}(p)$ & $\mathrm{r}(p)$ \\
\hline \multirow[t]{4}{*}{$\begin{array}{l}\text { Perceptions } \\
\text { of death }\end{array}$} & $\begin{array}{l}\text { Negativity } \\
\text { towards death }\end{array}$ & $\begin{array}{c}.11 \\
(.247)\end{array}$ & & & & & & \\
\hline & $\begin{array}{l}\text { Anxiety } \\
\text { regarding death }\end{array}$ & $\begin{array}{c}.01 \\
(.930)\end{array}$ & $\begin{array}{c}.12 \\
(.218)\end{array}$ & & & & & \\
\hline & Interest in death & $\begin{array}{c}.29 \\
(.002)\end{array}$ & $\begin{array}{c}.06 \\
(.510)\end{array}$ & $\begin{array}{c}.41 \\
(<.001)\end{array}$ & & & & \\
\hline & $\begin{array}{l}\text { Respect for the } \\
\text { will to live }\end{array}$ & $\begin{array}{c}.04 \\
(.647)\end{array}$ & $\begin{array}{c}-.09 \\
(.374)\end{array}$ & $\begin{array}{c}-.04 \\
(.711)\end{array}$ & $\begin{array}{c}-.01 \\
(.919)\end{array}$ & & & \\
\hline $\begin{array}{l}\text { EOL } \\
\text { care stress }\end{array}$ & & $\begin{array}{c}.33 \\
(<.001)\end{array}$ & $\begin{array}{c}.01 \\
(.890)\end{array}$ & $\begin{array}{c}-.04 \\
(.673)\end{array}$ & $\begin{array}{l}.18 \\
(.066)\end{array}$ & $\begin{array}{c}-.02 \\
(.860)\end{array}$ & & \\
\hline $\begin{array}{l}\text { Emotional } \\
\text { intelligence }\end{array}$ & & $\begin{array}{c}-.11 \\
(.270)\end{array}$ & $\begin{array}{c}-.05 \\
(.606)\end{array}$ & $\begin{array}{c}.02 \\
(.809)\end{array}$ & $\begin{array}{c}.01 \\
(.943)\end{array}$ & $\begin{array}{c}.26 \\
(.007)\end{array}$ & $\begin{array}{c}.01 \\
(.890)\end{array}$ & \\
\hline $\begin{array}{l}\text { EOL } \\
\text { care attitude }\end{array}$ & & $\begin{array}{l}-.12 \\
(.220)\end{array}$ & $\begin{array}{c}-.24 \\
(.013)\end{array}$ & $\begin{array}{c}-.23 \\
(.017)\end{array}$ & $\begin{array}{c}-.06 \\
(.561)\end{array}$ & $\begin{array}{c}.16 \\
(.098)\end{array}$ & $\begin{array}{c}.02 \\
(.873)\end{array}$ & $\begin{array}{c}.21 \\
(.028)\end{array}$ \\
\hline
\end{tabular}

EOL=End-of-life 
Table 4. Factors influencing Attitudes towards End-of-Life Care

$(N=111)$

\begin{tabular}{lccccccc}
\hline Variables & $\mathrm{B}$ & $\mathrm{SE}$ & $\beta$ & $\mathrm{t}$ & $p$ & Tolerance & VIF \\
\hline (Constant) & 2.88 & .18 & - & 16.45 & $<.001$ & - \\
Academic degree* $^{*}$ & 0.17 & .06 & .23 & 2.63 & .010 & .91 & 1.10 \\
Experiences of patient death* $^{*}$ & 0.08 & .04 & .18 & 2.10 & .038 & .93 & 1.08 \\
Negativity towards death & -0.06 & .03 & -.17 & 2.01 & .047 & .98 & 1.02 \\
Anxiety regarding death & -0.05 & .02 & -.21 & 2.47 & .015 & .98 & .02 \\
Emotional intelligence & 0.05 & .03 & .18 & 2.05 & .042 & .98 \\
& & & $\mathrm{R}^{2}=.247$, Adj. $\mathrm{R}^{2}=.211, \mathrm{~F}=6.89, p<.001$ & 1.02 \\
\end{tabular}

*Dummy variables: Academic degree (1=associate, $0=$ bachelor's degree or higher); Experiences of patient death $(1=11$ or greater, $0=1 \sim 10)$; VIF=Variance inflation factor.

wards EOL care was $24.7 \%\left(\mathrm{~F}=6.89, p<.001, \mathrm{R}^{2}=.247\right.$, Adj. $\mathrm{R}^{2}=$ .211).

\section{DISCUSSION}

Yoshiyuki [9], who developed the tool for perceptions of death, categorized the subdomains of perception of death into people affirming death (a score of at least 3.2), people with intermediate responses (a score between 2.5 and 3.2), and people denying death (a score of less than 2.5). It has been reported that nurses cannot provide comforting nursing care for dying patients and their families if they have negative perceptions of death [10]. In this study, NICU nurses scored 3.16 out of 5 points on average for perceptions of death, which is higher than the score of 2.85 points reported for nurses by Cha [19], which was generally regarded as an intermediate response. The distribution of scores by subdomain was 3.56 points for negativity towards death, 3.09 points for respect for the will to live, 3.07 points for anxiety regarding death, 3.02 points for positivity towards death, and 2.78 points for interest in death. While these results are broadly similar to those reported by Cha [19] in terms of the highest and lowest subdomains, the ordering of the subdomains is slightly different. This may be attributed to differences in subjects' circumstances, including age, academic degree, and affiliated department. In particular, in this study and Cha's study [19], scores for negativity towards death were high, and the quality of patients' and their families' lives may deteriorate if nurses experience limitations while caring for patients in pain due to negative perceptions of death [12]. Therefore, efforts to reduce negativity towards death through appropriate education on death are necessary.

In this study, the subjects' score for EOL care stress was 3.61 out of 5 points. This is lower than the score of 3.90 points reported by Jang [15], who used the same tool, but it shows a higher than medium stress level. NICU nurses cannot avoid emergencies or patients' deaths, and they indicated that they experienced high levels of EOL care stress due to the frequent situations involving death [15]. In this study, among the subdomains for stress of EOL care, the score for difficulties involved in related to EOL care was 3.67 points, compared to 3.65 points for difficulties in the physical and structural environment, 3.63 points for lack of knowledge, and 3.49 points for emotional stress. This result is similar to that reported by Jang [15], in that the highest scores were reported for difficulties involved in related to EOL care. In the study conducted by Ji and You [25], in which a different tool was used but similar underlying stress factors were analyzed, excessive workload was shown to be the main underlying stress factor. Therefore, support from medical institutions, including appropriate human resource allocation and system improvement, in order to reduce the workload is necessary, as the workload may increase during EOL care due to its technical demands.

Most previous studies on emotional intelligence in nurses were correlational studies, focusing on the relationship between variables related to emotional intelligence and organizational performance, and most reported that high emotional intelligence had positive effects [9]. In this study, the emotional intelligence of the subjects was 4.66 points out of a total of 7 . In the subdomains of emotional intelligence, self-emotion appraisal received 4.89 points, other's emotion appraisal received 4.86 points, use of emotion received 4.24 points, and regulation of emotion received 4.63 points. These results are very similar to those reported by Ko and Kim [18], and indicate that the nurses had a high ability to understand and express their own emotions and to understand and receive other's emotions, but were less able to utilize emotions for constructive activities and personal performance and to overcome and control psychologically disturbing situations. In a study by Kang and Bang [26] on NICU nurses' experiences with EOL infant care, many nurses reported that they did not know how to cope with grieving parents and that they responded passively. This could be seen as a lack of the ability to utilize or control emotions in psychologically disturbing situations, such as having to face death. Emotional intelligence is 
a factor useful for minimizing various conflict situations [12]. Emotion utilization and control could be improved through practice and training, and as emotional intelligence is made possible by providing appropriate compensation within a suitable system [27], programs to improve the emotional intelligence of nurses should be developed.

However, significant differences were found in the emotional intelligence of NICU nurses according to their position, academic degree, and whether they had received EOL care training. This is partially consistent with the results of the study conducted by Ha and Jeon [28] using the same tool. Emotional intelligence was higher among those with at least a bachelor or a master's degree than among those with an associate degree, and it was higher among those who had received EOL care education than among those who had not. This is further evidence of the need for education in order to improve nurses' ability to understand one's and others' emotions and to control and utilize one's emotions, and there is a need for administrative and financial support from hospitals and relevant departments, including educational institutions, for continued and sustainable education in clinical settings.

The mean score for attitudes towards EOL care, the dependent variable of this study, was 2.77 points out of 4 . Based on the study conducted by Frommelt [23], the developer of the tool, the subjects' attitudes towards EOL care in this study could be regarded as positive, according to the interpretation that an average of at least 2 points is a normal level. However, since the score for attitudes towards EOL care was 2.94 points in another study of nurses in nursing hospitals that used the same tool, this study recorded relatively low scores compared to others. Moreover, although a direct comparison may be difficult because a different tool was used, NICU nurses showed a score of 3.27 out of 5 points for attitudes towards EOL care in the study of Wi and Kang [4]. If that score is converted to a 4-point scale, it can be seen that the scores of the subjects in this study are lower. This suggests that NICU nurses experience more sadness, guilt, and regret than nurses dealing with dying adult patients [6], and that this negative sentiment affects their attitudes towards EOL care. Although the importance of EOL care education and support has already been elucidated in studies published in several foreign journals [29], there is a need for solutions in Korea, including the development of programs and systems to improve EOL care education and attitudes toward EOL care, especially because no principles or standards have been articulated for domestic neonatal EOL care.

The relationships between attitudes towards EOL care and the general characteristics of the NICU nurses were similar to the results for emotional intelligence, in that significant differences were found according to academic degree and the num- ber of times that nurses had experienced the death of a patient. The results were more positive for those with at least a master's degree than for those with an associate or a bachelor degree, which is consistent with the results of the study conducted by Ali and Ayoub [7], who found that higher academic degrees were associated with higher emotional intelligence. This further underscores the importance of education. It is suggested that EOL care education should be implemented in the undergraduate curriculum, and Cho and Kim [22], who studied the effects of a death education program on nursing students, showed that the death education program positively affected attitudes towards EOL care and reduced levels of anxiety regarding death. Therefore, plans should be made to improve attitudes towards EOL care by providing an environment in which nurses can receive continuing education and by developing and implementing an EOL care education program.

Another factor affecting attitudes towards EOL care was the number of times that subject had experienced the death of a patient, with more positive attitudes observed when that number was 11 or higher. This result is consistent with those of previous studies $[3,12,24]$ that reported positive attitudes towards EOL care to be associated with frequent exposure to patients' deaths. Noh et al. [24] interpreted these findings as suggesting that occupational attitude and value satisfaction as a medical professional may have had a positive effect on attitudes towards EOL care, due to the diversity of work experience and work adaptability. Hong et al. [12] explained that nurses come to understand dying patients better when they are more frequently exposed to death. In clinical practice, veteran nurses with EOL care experience, when working with new nurses, can proactively utilize the preceptor system, which provides relevant nursing skills and emotional support. In addition, since repeated EOL care experiences increase nurses' EOL care capacity and improve their understanding of dying patients, a program should be developed for nurses to share their EOL care experiences, and a protocol should be established with administrative and institutional support that could provide help in real clinical situations.

The analysis of correlations among the subjects' perceptions of death, EOL care stress, emotional intelligence, and attitudes towards EOL care showed that attitudes towards EOL care had a significant negative correlation with negativity towards death and anxiety regarding death, and a significant positive correlation with emotional intelligence. This is consistent with previous studies reporting that lower scores for negativity towards death [12] and more positive perceptions of death [24] were associated with more positive attitudes towards EOL care. Braun, Gordon, and Uziely [30] stated that a negative attitude towards death increased nurses' anxiety re- 
garding death, thereby hindering their ability to provide appropriate EOL care to dying patients and their families. As the nurses have a major influence on the circumstances of EOL care according to how they perceive death, education should focus on reducing negative perceptions and improving positive perceptions of death. In addition, positivity towards death, a subdomain of perceptions of death, was positively correlated with EOL care stress, which can be interpreted as indicating that positive perceptions of death instead induced stress during EOL care. Therefore, it is also important for educational programs to improve nurses' perceptions of death to promote strategies for managing EOL care stress. Next, emotional intelligence was positively correlated with attitudes towards EOL care, which can be interpreted as reflecting the fact that it is an important factor influencing efficient communication and reflects the ability to sympathize with the patient's emotions and to establish trust. EOL care education programs should include content on emotional intelligence [27].

However, in this study, there was no significant correlation between EOL care stress and attitudes towards EOL care, in contrast to Ji and You [25], who reported a significant negative correlation between EOL stress and attitudes towards EOL care. Although a study [15] indicated that NICU nurses experienced a higher level of EOL care stress than nurses from other departments, no study has investigated the factors influencing this relationship or the correlation between these two variables, suggesting a need for further studies in the future.

Academic degree, negativity towards death, anxiety regarding death, and emotional intelligence were identified as factors influencing attitudes towards EOL care. Their explanatory power was $21.1 \%$, and the most influential factor was academic degree. In the studies of Noh et al. [24] and Ali and Ayoub [7] on NICU nurses, the higher the level of education, the more positive their attitudes were towards EOL care, as in this study. In combination with findings that higher academic degrees were associated with higher levels of organizational commitment, it may be the case that more highly-educated nurses help to create positive perceptions of the value of EOL care, thereby promoting positive attitudes towards EOL care through positive emotions and motivation. To this end, it is necessary to support from nursing staff and institutional-level support, as well as cooperation for academic work within nursing departments through continuous exchanges among medical and educational institutions.

The results of this study are difficult to generalize, as NICU nurses were only sampled from certain areas. In addition, the explanatory power of the factors affecting attitudes towards EOL care was relatively low (21.1\%), and there are limitations in the degree to which the tools used in this study could evaluate the specific job characteristics of NICU nurses, since they were not developed for NICU nurses. Further research into factors influencing attitudes towards EOL care and correlations between relevant variables is suggested due to the lack of previous studies on variables related to EOL care among NICU nurses. In particular, future research into emotional intelligence, which is a novel variable in analyses of factors related to attitudes towards EOL care, is suggested.

\section{CONCLUSION}

This study examined the effects of NICU nurses' perceptions of death, EOL care stress, and emotional intelligence on attitudes towards EOL care, in order to provide basic data to support the development of initiatives for improving NICU nurses' attitudes towards EOL care. In this study, the factors found to influence NICU nurses' attitudes towards EOL care were academic degree, the number of times the nurse had experienced the death of a patient, negativity towards death, anxiety regarding death, and emotional intelligence. More positive attitudes towards EOL care were associated with higher academic degrees, more frequent experiences of a patient's death, less negativity towards death, less anxiety regarding death, and higher emotional intelligence.

Based on these results, EOL care education programs and protocols are necessary to improve NICU nurses' attitudes towards EOL care, content aiming to improve emotional intelligence should be added to educational programs, and education should focus on reducing negative perceptions and fostering positive perceptions of death. In addition, administrative and institutional support from hospitals should be provided to support such initiatives.

\section{Conflict of interest}

No existing or potential conflict of interest relevant to this article was reported.

\section{REFERENCES}

1. Statistics Korea. 2017 Life table for Korea [Internet]. Daejeon: Statistics Korea; 2017 [cited 2017 December 15]. Available from: http://kostat.go.kr/portal/korea/kor_nw/2/2/1/index.board?b mode $=$ read $\& a S e q=366808$.

2. Dessy E. Effective communication in difficult situations: Preventing stress and burnout in the NICU. Early Human Development. 2009;85(10):S39-S41.

https://doi.org/10.1016/j.earlhumdev.2009.08.012

3. Yu M. Work stress, turnover intention and burnout among nurses in neonatal intensive care units. Journal of Korean Academy of Nursing Administration. 2011;17(1):115-126. 
https://doi.org/10.11111/jkana.2011.17.1.115

4. Wi DH, Kang SJ. Relationship among nurses' knowledge, attitude towards palliative care and perception of death in neonatal intensive care units. Child Health Nursing Research. 2016;22(4):257264. https://doi.org/10.4094/chnr.2016.22.4.257

5. Chen CH, Huang LC, Liu HL, Lee HY, Wu SY, Chang YC, et al. To explore the neonatal nurses' beliefs and attitudes towards caring for dying neonates in Taiwan. Maternal and Child Health Journal. 2013;17(10):1793-1801.

https://doi.org/10.1007/s10995-012-1199-0

6. MacDermott C, Keenan PM. Grief experience of nurses in Ireland who have cared for children with an intellectual disability who have died. International Journal of Palliative Nursing. 2014;20(12): 584-590. https://doi.org/10.12968/ijpn.2014.20.12.584

7. Ali WGM, Ayoub NS. Nurses' attitudes toward caring for dying patient in Mansoura University Hospitals. Journal of Medicine and Biomedical Sciences. 2010;1(1):16-23.

8. Noh YJ, Han SS, Ahn SH, Kim CG. Hospice and death. 1st ed. Seoul: Hyeonmunsa; 1997. p. 1-502.

9. Yoshiyuki I. A study on development of a view of life and death scale and relationships among its elements [dissertation]. Seoul: Korea University; 2002. p. 1-97.

10. Seo MJ, Kim JY, Kim SH, Lee TH. Nurses attitudes towards death, coping with death and understanding and performance regarding EOL care: Focus on nurses at ED, ICU and oncology department. The Korean Journal of Hospice and Palliative Care. 2013;16(2): 108-117.

11. Jo KH, Han HJ. Nurses' painful experiences through terminal patient. Journal of Korean Academy of Nursing. 2001;31(6):10551066. https://doi.org/10.4040/jkan.2001.31.6.1055

12. Hong E, Jun M, Park ES, Ryu E. Death perceptions, death anxiety, and attitudes to death in oncology nurses. Asian Oncology Nursing. 2013;13(4):265-272.

https://doi.org/10.5388/aon.2013.13.4.265

13. An MS, Lee KJ. Awareness of good death and attitudes toward terminal care among geriatric hospital nurses. The Korean Journal of Hospice and Palliative Care. 2014;17(3):122-133.

https://doi.org/10.14475/kjhpc.2014.17.3.122

14. Katsuhiko H. Contrast education for death. 3rd ed. Lee OH, translator. Youngin: Moonumsa; 2002. p. 1-218.

15. Jang SH. Neonatal intensive care unit nurses' stress of end of life care for high-risk newborn [master's thesis]. Seoul: Ewha Womans University; 2013. p. 1-67.

16. Wong CS, Law KS. The effect of leader and follower emotional intelligence on performance and attitude: An exploratory study. The Leadership Quarterly. 2002;13(3):243-274. https://doi.org/10.1016/s1048-9843(02)00099-1

17. Por J, Barriball L, Fitzpatrick J, Roberts J. Emotional intelligence: Its relationship to stress, coping, well-being and professional performance in nursing students. Nurse Education Today. 2011;31
(8):855-860. https://doi.org/10.1016/j.nedt.2010.12.023

18. Ko HR, Kim JH. The relationships among emotional intelligence, interpersonal relationship, and job satisfaction of clinical nurses. The Journal of Korean Academic Society of Nursing Education. 2014;20(3):413-423. https://doi.org/10.5977/jkasne.2014.20.3.413

19. Cha YR. Study on the nurses' attitude to death in Korea: Centering on university hospital in Jeollabuckdo province [master's thesis]. Iksan: Wonkwang University; 2005. p. 1-46.

20. Jung HW, Kim CH. A study on the effect of emotional intelligence on organizational citizenship behavior. Journal of Human Resource Management Research. 2007;14(3):167-186.

21. Lee YB, Ko MS. The effect of clinical nurses' communication competency and emotional intelligence on organizational performance. Journal of Korean Clinical Nursing Research. 2015;21(3): 347-354. https:// doi.org/10.22650/JKCNR.2015.21.3.347

22. Cho HJ, Kim ES. The effect of the death education program on the death anxiety and attitudes toward nursing care of the dying patients of nursing student. The Korean Journal of Hospice and Palliative Care. 2005;8(2):163-172.

23. Frommelt KHM. The effects of death education on nurses' attitudes toward caring for terminally ill persons and their families. American Journal of Hospice and Palliative Medicine. 1991;8(5): 37-43. https://doi.org/10.1177/104990919100800509

24. Noh SS, Lee CK, Sung YH. Predictors of terminal care performance of clinical nurses for cancer patients. Journal of Korean Critical Care Nursing. 2016;9(2):61-70.

25. Ji SI, You HS. The impact of clinical nurses' terminal care attitude and spiritual health on their terminal care stress. The Korean Journal of Hospice and Palliative Care. 2014;17(4):232-240. https://doi.org/10.14475/kjhpc.2014.17.4.232

26. Kang HJ, Bang KS. Neonatal intensive care unit nurses' experience in caring for infants who are dying. Child Health Nursing Research. 2013;19(4):252-261.

https://doi.org/10.4094/chnr.2013.19.4.252

27. Baek M, Jang KS. Development and verification on the effectiveness of coaching program for nurses. Journal of Health Informatics and Statistics. 2016;41(1):57-66. https://doi.org/10.21032/jhis.2016.41.1.57

28. Ha JY, Jeon SY. The effects of humanistic knowledge and emotional intelligence on communication skills of nurses. The Journal of Korean Academic Society of Nursing Education. 2016;22(3): 264-273. https://doi.org/10.5977/jkasne.2016.22.3.264

29. Kain VJ. An exploration of the grief experiences of neonatal nurses: A focus group study. Journal of Neonatal Nursing. 2013;19(2): 80-88. https://doi.org/10.1016/j.jnn.2012.04.001

30. Braun M, Gordon D, Uziely B. Associations between oncology nurses' attitudes towards death and caring for dying patients. Oncology Nursing Forum. 2010;37(1):E43-E49.

https://doi.org/10.1188/10.onf.e43-e49 